\title{
YOGA FOR MENTAL HEALTH OF CHILDREN: A SHORT REVIEW
}

\author{
Farahnaz Davari*, Nahal Sadiri**, Arghavan Shariat***, Soh Kim Geok**** \\ Author for correspondence: Nahal Sadiri - nahalsadiri@gmail.com \\ *Department of Psychology, Faculty of Educational Science, Islamic Azad University Isfahan (Khorasgan) \\ Branch, Isfahan, Iran \\ **Department of Sport Studies, Faculty of Education, University Putra Malaysia, Malaysia \\ ***Department of Psychology, Faculty of Literature and Humanities, Islamic Azad University of Shahrekord, \\ Isfahan, Iran \\ ****Department of Sport Studies, Faculty of Education, University Putra Malaysia, Malaysia
}

\section{A B S T R A C T}

Introduction: This review paper aims to introduce yoga as a method for dealing with stress of children, and discusses how it can help them to balance body and emotion. Children need to listen inward: to their bodies, ideas and their feelings. Yoga helps children on being self aware and taking part in social activities. Method: This review attempted to gather the relevant papers that were previously published on the subject. PubMed, Scopus, and Google Scholar were the sources for findings the articles. Only the articles that were published not later than 2005 were selected. Results: Nowadays, children's expectations are higher than in the past, and their interest on the internet, media, and other communication technologies has increased. Using these media devices and the time that they spend on it may influence their lifestyles negatively and cause stress. While these technologies are very useful in their life for communication even in learning and entertainment, these sources can also lead to undeveloped attention. This article is suggesting yoga as a helpful method for children to deal with their stress, and to increase their well-being, mental health, and positive feelings. Conclusion: Yoga aids to improve physical and mental health among children and helps students in enhancing resilience, mood and self-regulation skills related to emotion and stress.

Keywords: Yoga; Children; Mental health; Stress 
Nowadays, various new options and standards are imposed upon children. New resources are available for the new generation; thus, a good performance is expected from them ${ }^{1,2}$. Different aspects such as family, school, and media could inspire children, leading to the expectations ${ }^{3,4}$. Those demands cause stress in children's lives and affects their performances' evaluation processes. High stress level negatively influences children's health, and could cause anxiety, insomnia, hypertension, and muscle pain, as well as damages to their immune system ${ }^{5,6}$. Previous researches supported that stress also could lead to heart disease, depression, and overweight or even to compromises to general health ${ }^{7-9}$. Some of young parents who are responsible for taking care of the children might transfer their tension to their children, which should be noted as it could cause trouble for their families ${ }^{10,11}$. On the other hand, children learn to internalize the stress of selfimposed expectations set by their caregivers, schools, and society, which can result in some problems such as anxiety for them ${ }^{12}$. Children can hide their stress and concerns from their parents, as they do not like to make their parents worried and upset, or being an additional stress for their parents. They like to follow their natural development process, and they are interacted to other children that is very different from those of adults $^{13}$. Children are responsible for their own well-being, and they are capable to be partners with their families, friends and society. However, development of children's potential depends on the environment of society ${ }^{14}$.

This review paper discusses yoga, based on the previous researches, as a potential treatment of stress in children. Yoga creates emotional balance between their body and mind. In addition, yoga is a cost-effective method that can be easily employed by all groups of individuals, and can be adapted to all types of lifestyles $8,9,15,16$. As suggested, yoga teaches people to listen to their inner rhythms; thus, it can be very helpful for children to listen to their bodies, feelings, and ideas. Yoga also contributes to mental health maturation and physical health progression resulting in improvement in children's attention, self-esteem empowerment, and self-regulation ${ }^{1,17}$. Children's developments should be based on their unique personality in order to provide the required balance between their strengths and expectations from the society. Yoga helps them to develop ways of contribution in society $8,9,15$.

\section{METHODS}

This review collected the relevant and valuable published researches related to yoga and summarized those that are easy and practical guideline for parents, who are interested to care about their children's health. PubMed, Scopus, and Google Scholar were the sources for findings the articles. The keywords including: yoga, children, and health. Only the articles that were published not later than 2005 were selected. Among 22 papers, those with clear methodology and same subjects were selected ( 11 papers).

\section{RESULTS}

\section{a) Children and mental health}

Children share more values with their parents than their relatives; however, they spend more time with their own generation than with their parents' generation that might be a reason for reduction in the statistics of drug-usage and breaking the norms. Studies showed that young people nowadays are more worried than the equivalent past generations $^{18-20}$. Large numbers of young people have been diagnosed to have conditions such as attention deficit hyperactivity disorder (ADHD) $)^{2,3}$.

The pressure for succeeding in school has been increased among children compared to the past ${ }^{2,6}$. They are challenging themselves with increased stress on education and self-control. Thus, currently there are several psychological disorders among young people such as overthinking and worrying, sleeping problems, hopelessness and stress ${ }^{19-21}$. Mental health disorders among children has been shown to be 
common in the west, and over the world. In 2012, the European Union Youth (EUY) reported that 10-20\% of young people suffer from mental illnesses while one out of five struggles are related to emotional and behavior problems ${ }^{21}$. As it is known, majority of adolescents in the world are healthy, though $20 \%$ may experience mental health issues ${ }^{22}$. In a recent survey, it was reported that almost $15-20 \%$ of Norwegian children aged between ${ }^{3-17}$ have had less functioning abilities due to mental problems such as anxiety, depression, and behavioral disorders'. In total, due to the psychological and biological changes there are more psychological challenges around adolescents'. During the growth process, children might face some pressures from the family, school and other social settings that expect them to display good performance, and adjust rapidly with changing developments in the society 8,10 . This is very challenging for children, their teachers, and their parents for achieving positive mental healthy mindsets ${ }^{23}$.

Passing the period of childhood into adulthood is a difficult time. In dealing with physical changes, children's personality will be developed and their independency from their parents will be increased. This process puts a lot of pressure on them as they would face some different environments, such as academic, job market, and relationship-wise and their issues such as succeeding in school, being popular and having a fit body ${ }^{1,24}$. In this stage they like wearing branded clothes and having latest technology gadgets etc. As it can be clearly seen this expectation creates stress and can negatively affect their mental health and well-being, as well as their performance in school. Children suffering from bullying at school and every related behavior are having problem in attention and self-control such as ADHD deficit disorder, ADD, sleep disorders, obesity, computer dependency, substance abuse, and these problems can cause less motivation in school, and also dropping out ${ }^{2,25,26}$. Recently, the dropout rates in EU and USA high schools are about 3\% in spite of policies and special measures'. In addition, schools challenge students as they are keen on the internet, social media and gaming more than school's curriculum. Having short daily yoga training can be helpful to decrease these issues, however this training should be joyful and easy to do with no age limitation.

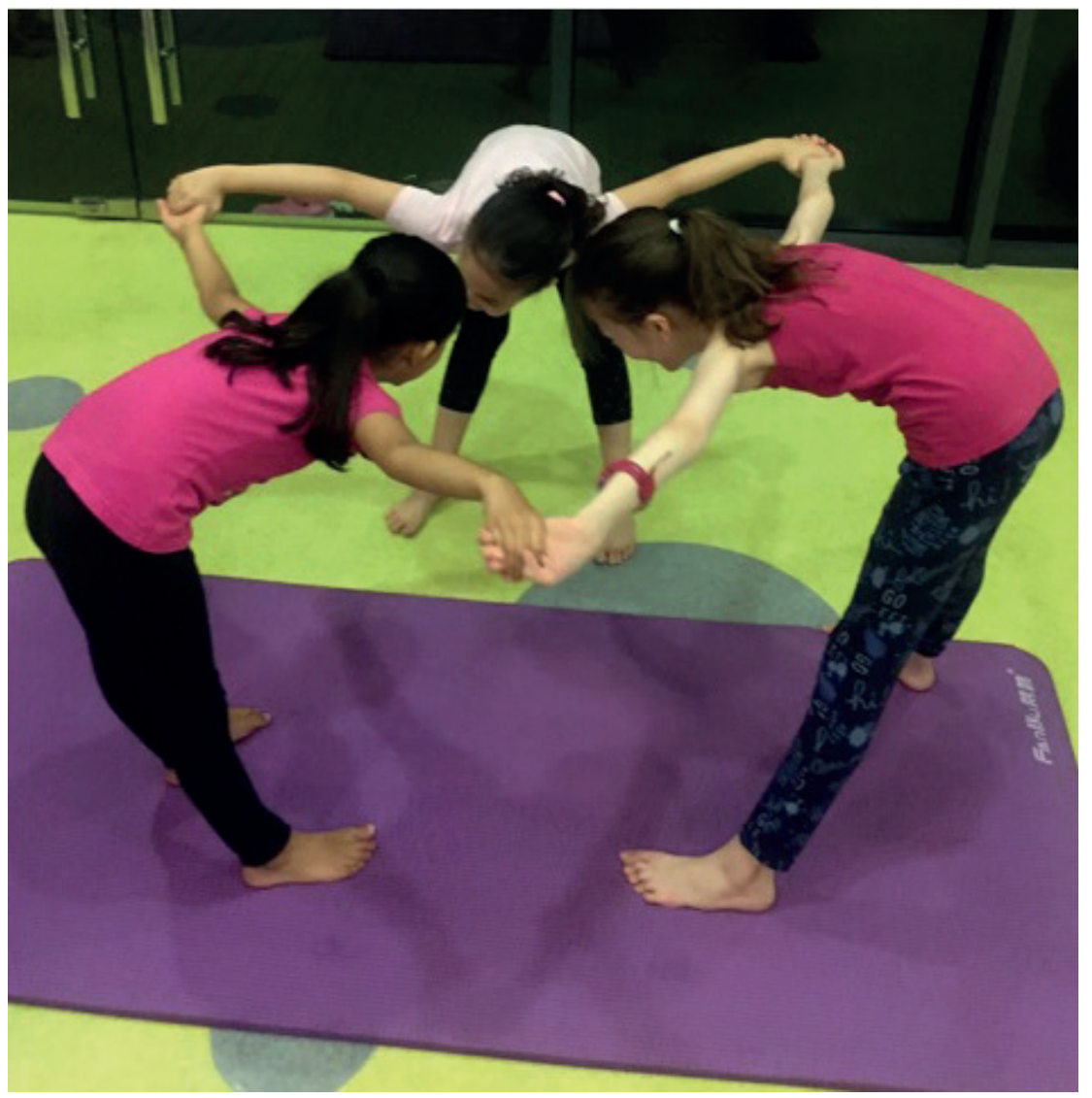

Figure 1: Easy type of yoga training without age limitation for the children 


\section{b) Yoga in children's lives}

The ancient practice of yoga helps children to deal with stress and have positive mental health. The author of yoga's education book in India claimed that as a nut could be protected by shell, yoga could protect children against challenges and problems. In the article titled "Effect of yoga on mental health in children", Shirley mentions that he is one of the best researchers in the world ${ }^{27}$. Shirley concludes that yoga can help children to improve their physical and mental health. In reviewing other research, it was found that yoga is the cause of resilience in children and enhance it in them, and that it can also improve their mood, self-regulation, as well as emotions and stress $^{28}$. These findings support that yoga is an important method to cope with stress and selfregulation in children's perspective in life. Therefore, those researchers that are looking for the best way of developing health in children and young people might ask that what can be done to make a happy environment, and create opportunities to develop their potentials (Figure 2).

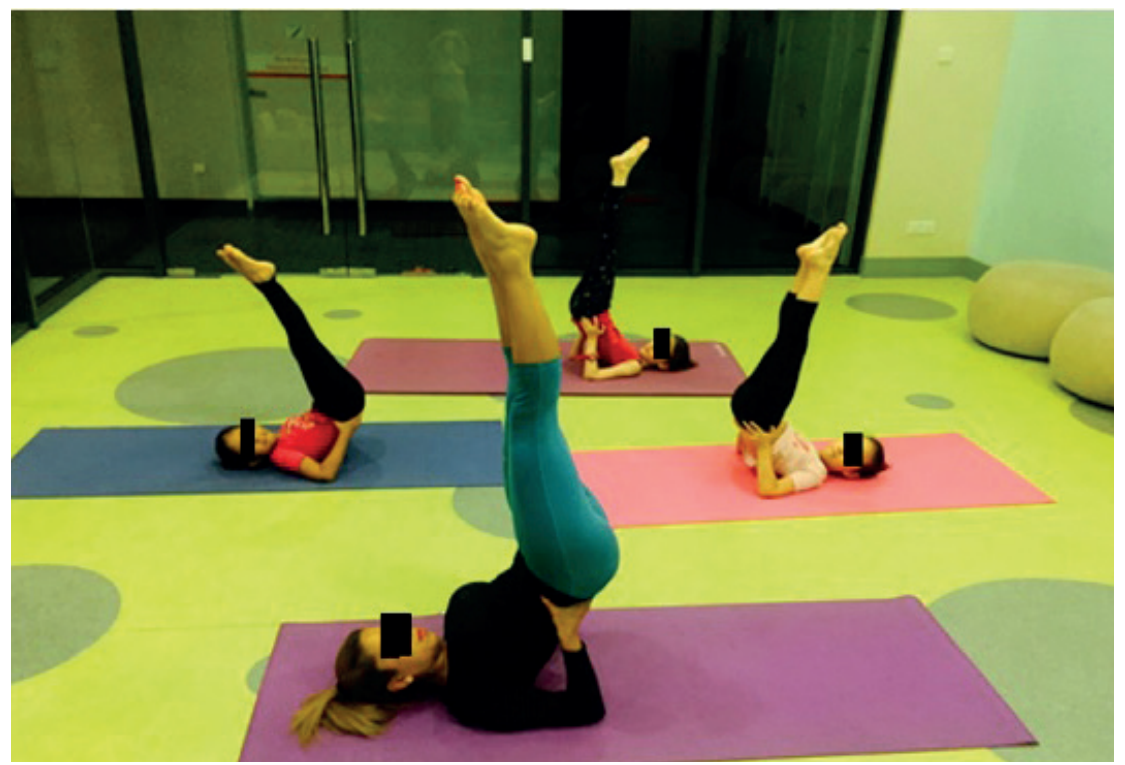

Figure 2: Yoga training to develop physical abilities of children

With regard to this question, this article aims to provide an argument regarding the reasons for choosing yoga. Firstly, yoga could be a better solution for treatments of children with mental health problems who are undergoing pharmacological treatments, as these medications could have immediate and long-term negative side effects. Thus, there seems to be a need of finding other solutions of physical treatment such as yoga for empowerment to give children and young people a tool for developing self-reflection, self-protection, and selfdevelopment (Figure 3-4).

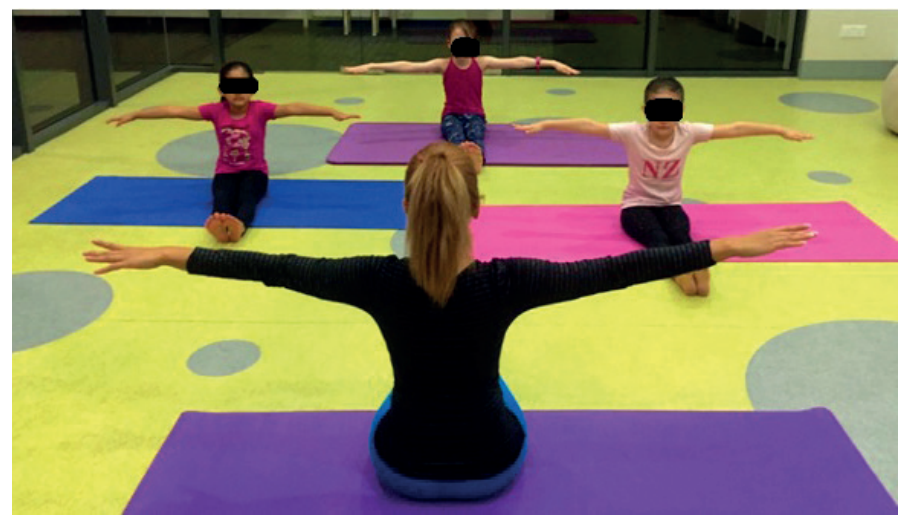

Figure 3: Yoga as a practical way to improve the balance and concentration in children

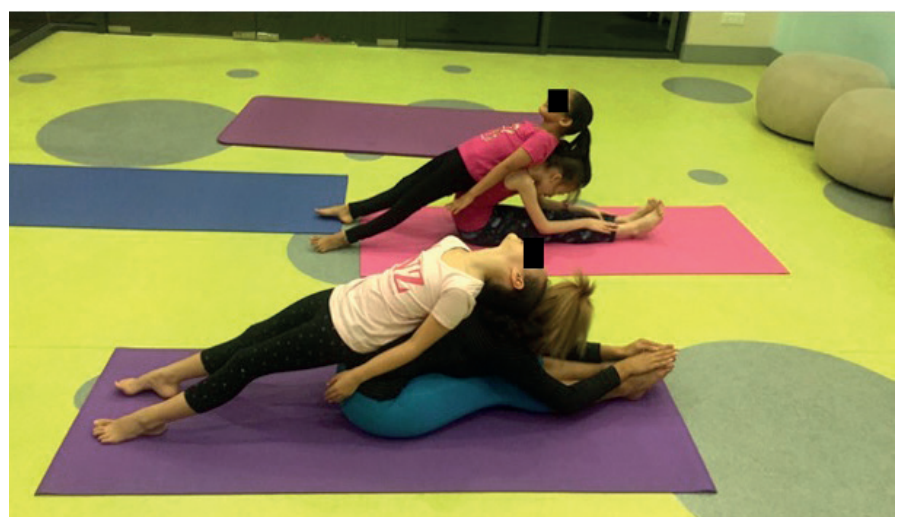

Figure 4: Stretching and releasing the stress in Yoga 
As it is proved that yoga has the ability to stabilize the mind and improve overal health, a global interest has been increased for yoga in recent decades. Developing a healthy relationship with parents and teachers, and being adjusted with them emotionally, mentally, and behaviorally would result in better mental health and well-being ${ }^{1,17}$.
Yoga has been spread all over the world as an ancient Indian method of improving body and mind simultaneously. Yoga consists of certain standing, sitting, and lying techniques that are synchronized with breathing, hand poses and meditation (Figure 5).

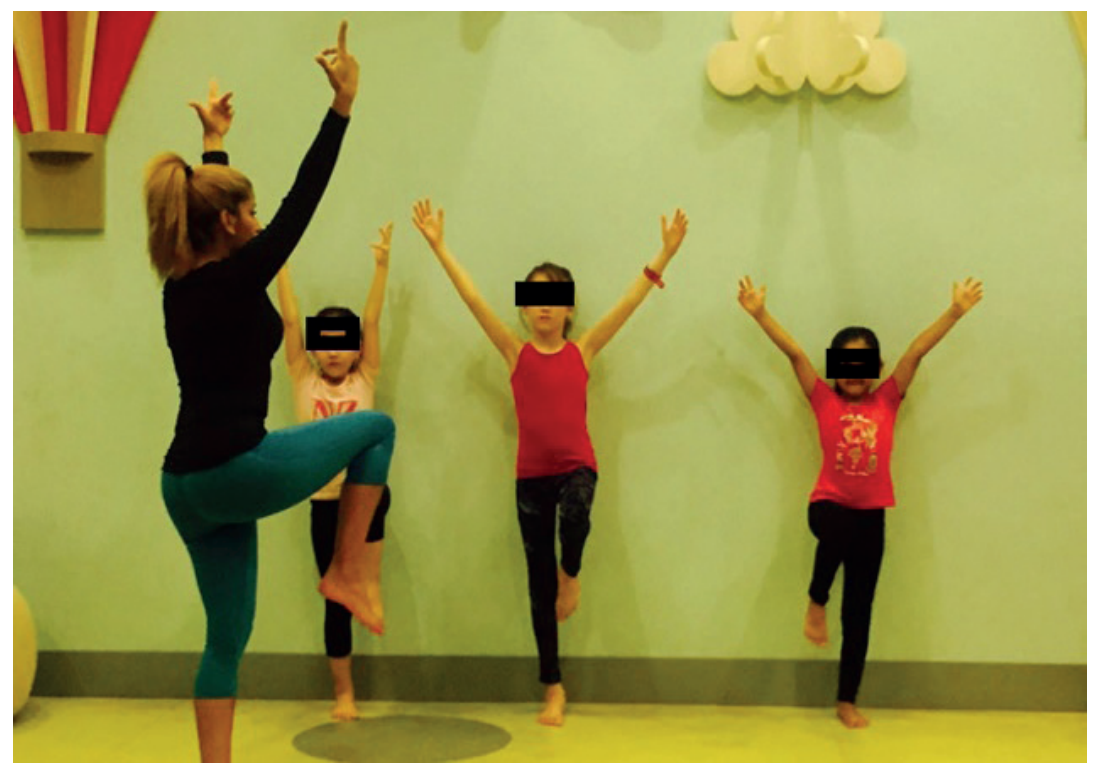

Figure 5: Standing and finding the suitable balance

The knowledge and experience about appropriate and different movements is very important. It has been claimed that yoga has positive impact on the physical and mental health of individuals. Recently some of these claims has been scientifically verified indicating that yoga exercises are very useful for mental and physical health of children and young people ${ }^{28}$.

It should be noted that, there are different methods to measure the improvements among subjects, to see if there was any feedback in response to yoga exercise training, or if it was useful to decrease their stress. A groups of questionnaires for psychological parameters ${ }^{29,30}$ and physical parameters $32-35$ are suggested by researchers, that are also useful for adults.

Yoga could be used as a suitable intervention in childhood and adolescents to reduce stress especially in the school environment. The study conducted by Khalsa on high school students revealed that yoga could have a positive influence on emotional balance, and decrease the level of stress among this group ${ }^{8}$. It was also hypothesized that yoga might help the younger children and youth to increase self-regulation, and facilitate their wellbeing for positive social interactions and better school performance. Other research also offered that yoga has significant effect on health capacities and coping with stress. Findings of this article showed that yoga aids to mental health via down-regulation of the hypothalamic-pituitary-adrenal (HPA) axis of the sympathetic nervous system that these results are in line with numerous evidences ${ }^{7}$. Application of yoga among children can help in development process, reduce daily stress, weight management, and decrease emotional and behavioral problems. Yoga is like a supplement for improving focus and attention'. Another positive point is that yoga is appropriate for all of the students in school at all the age groups. Some other yoga studies on children showed significant enhancement in concentration, self-regulations, self-awareness, consciousness, behavioral and emotional development, selfconfidence, and reducing stress ${ }^{1,16,35,36}$. As mentioned above, yoga could be used as an assistant to medical treatment of mental illness with positive effects. Nevertheless, there is a need for further research to investigate the effects of only yoga as a therapy for treating mental disorders and in particular among children. According to Ross et al. ${ }^{28}$, yoga could be 
used as a comprehensive treatment for stress among children ${ }^{28}$. Moreover, yoga could develop motivation, internal locus of control, better sleep, and generally assist in healthy living. In addition, it helps to shift the action of self-awareness toward children's emotions, and also stabilize negative social and cultural influences including the common media pressure for being online and available ${ }^{15,17,28}$. Yoga is beneficial for improving focus and concentration, and better academic performance ${ }^{37}$. It can aid the children with attention problems ${ }^{38}$, and also in developing executive function. A group of studies agreed that yoga could help the children with special needs through rehabilitation processes ${ }^{39}$.

Clinical studies indicate that yoga improved academic performance and emotional balance. The mental benefits of yoga can also assist to stabilize heart rate as signals are sent from the brain to activate the parasympathetic nervous system. Furthermore, yoga reduces sympathetic activity resulting in better relaxation. Yoga has been shown to be effective in reducing anxiety in young people as well as in adults. As it has been mentioned, yoga develops mental health, resilience and self-regulation ${ }^{1,21}$. This article tends to think about how to use recommendations for introducing yoga into children and young people's lives, based on perspective on children maturation and childhood sociology. Yoga often has been promoted as a universal method of self-control for achieving balance between human development with philosophy and practice. Pedagogy of yoga needs to be understood specifically and adjusted to practitioners as a specific context. In addition, teaching yoga needs to be taken seriously with selfcontrol based on children's needs in daily lives, so it can be fun and playful for them.

\section{DISCUSSION}

As explained in this article, yoga is suitable for children with mental disorders. Practicing yoga every day will help individuals to face their problems in life with maturity and steadiness. There are many training and practice centers available in the world using private agencies and individuals for sessions with profit and non-profit. Lots of yoga studios exist and they organize sessions in different forms, and many people pay fees for using facilities and practicing yoga in these places. However, the majority of schools, preschools and public places of education do not involve yoga sessions in their program ${ }^{17,41}$, and it is suggested to be considered.

Notwithstanding, their first responsibility is to find talents and develop all potentials of children and young people. Nowadays, children require being involved in creative and interactive programs, and method in the accidentally teaching learning process'. This approach is suitable for learning yoga as well. Thus, yoga should be introduced to children and young people, so they can be adjusted with yoga as a powerful method of decreasing their stress. In any kind of emotional and social stressful situations, yoga could be used. Thus yoga may also help people from the social perspective, so it might affect the childhood period catching on civic activities and shaping a better society. As stated, practicing yoga has a potential for making better mental health of children and young people. Children and young people have the potential for developing themselves and their society, and yoga can create functional relationship of well-being for both groups.

Children are facing a lot of stressful situations such as rising expectations, and media usage in extensive ways in their daily lives in modern societies ${ }^{15}$. This article is suggests that children and young people might be able to manage their stress, self-regulation, and health with yoga. Shaktakhalsa is the first person that offered the idea of teaching yoga to children. She argued that children's yoga is not simplified version of yoga for adults, but it has to be a unique training intervention'. Khalsa also emphasized the importance of making yoga as a fun type of exercise for children ${ }^{8}$. Yoga instructors should be aware that yoga could strengthen children's self-esteem and their consciousness.

The findings of this short review, concluded that, all the previous researches accepted Yoga as an effective activity to affect the mental and physical condition of children. The presented techniques in previous researches were different, but the main aim was same, and most of them were focused on flexibility of joints with easy exercises. It should be noted that, the protocol of Yoga, should make 
the children happy and be such a fun, rather than a series exercise training protocol. For the further studies, it is suggested to compare the effect of different types of Yoga program on different physical and psychological parameters. Also, it is still not clear about the mechanism of this kind of effect on psychological parameters made by Yoga.

\section{REFERENCES}

1. Hagen I, Nayar US. Yoga for children and young people's mental health and well-being: research review and reflections on the mental health potentials of yoga. Front. psychiatry. 2014;5(35): 1 6. doi: $10.3389 /$ fpsyt. 2014.00035

\section{Shariat A, Shariat A, Abedi A, Tamrin SBM.} Physical activity as a prescription for the children with cerebral palsy. Russ. Open Med. J. $2014 ; 3(1): 1-4$

\section{Organization WH. International Classification of} Functioning, Disability, and Health: Children \& Youth Version: ICF-CY. Geneva: Who Press; 2007

4. Steinberger J, Daniels SR, Eckel RH, Hayman $L$, Lustig RH, McCrindle $B$ et al. Progress and challenges in metabolic syndrome in children and adolescents a scientific statement from the American Heart Association atherosclerosis, hypertension, and obesity in the young committee of the council on cardiovascular disease in the young; $c$. Circulation. 2009; 1 19(4):628-647. doi: 10.1161/ CIRCULATIONAHA.108.191394

5. Williams DP, Going SB, Lohman TG, Harsha DW, Srinivasan SR, Webber LS et al. Body fatness and risk for elevated blood pressure, total cholesterol, and serum lipoprotein ratios in children and adolescents. Am. J. Public Health. 1992;82(3):358363

6. Schroeder VM, Kelley ML. Associations between family environment, parenting practices, and executive functioning of children with and without ADHD. J. Child Fam. Stud. 2009;1 8(2):227-235. doi: $10.1007 / \mathrm{s} 10826-008-9223-0$
7. Khalsa SB, Hickey-Schultz L, Cohen D, Steiner N, Cope S. Evaluation of the mental health benefits of yoga in a secondary school: a preliminary randomized controlled trial. J. Behav. Health Serv. Res. 2012;39(1):80-90. doi: 10.1007/s1 1414$011-9249-8$

8. Sadiri SN, Mohammed M, Naji FL, Chian $C P$, Sangelaji B. Yoga as a treatment for musculoskeletal discomforts: a hypothesis. Rev. Pesqui. em Fisioter. 2016;6(3):236-246. doi: 10.17267/2238-2704rpf.v6i3.984

9. Ross A, Friedmann E, Bevans $M$, Thomas $S$. National survey of yoga practitioners: mental and physical health benefits. Complement. Ther. Med. 2013;21(4):313-323. doi: 10.1016/i. ctim.2013.04.001

10. Busse M, Stromgren $K$, Thorngate L, Thomas KA. Parents' responses to stress in the neonatal intensive care unit. Crit. Care Nurse. 2013;33(4):52-59. doi: $10.4037 / \operatorname{ccn} 2013715$

11. Widarsson $M 1$, Engström $G$, Rosenblad $A$, Kerstis B, Edlund B, Lundberg P. Parental stress in early parenthood among mothers and fathers in Sweden. Scand. J. Caring Sci. 2013;27(4):839847. doi: $10.1111 /$ i. $1471-6712.2012 .01088 . x$

12. Henry JP, Stephens PM. Stress, health, and the social environment: $A$ sociobiologic approach to medicine. New York: Springer Science \& Business Media; 2013.

13. Kamali S, Hassani F. Mental health and its relationship with stress coping strategies and emotional intelligence in female students at preuniversity level. J. Behav. Sci. 2013;7(1):49-56

14. Hill M, Tisdall K. Children and society. New York: Routledge; 2014.

15. Sherman KJ, Cherkin DC, Erro J, Miglioretti DL, Deyo RA. Comparing yoga, exercise, and a self-care book for chronic low back pain: a randomized, controlled trial. Ann. Intern. Med. 2005; 1 43(12):849-856

16. Lin KY, Hu YT, Chang KJ, Lin HF, Tsauo JY. Effects of yoga on psychological health, 
quality of life, and physical health of patients with cancer: a meta-analysis. Evidence-Based Complement. Altern. Med. 201 1;201 1:1-12. doi: $10.1155 / 2011 / 659876$

\section{Gururaja D, Harano K, Toyotake I, Kobayashi} H. Effect of yoga on mental health: Comparative study between young and senior subjects in Japan. Int. J. Yoga. 2011 ;4(1):7-12. doi: 10.4103/09736131.78173

18. Meltzer H, Gatward R, Goodman R, Ford T. The mental health of children and adolescents in Great Britain. HM Stationery Office; 2000

19. Wu P, Hoven CW, Bird HR, Moore RE, Cohen $P$, Alegria $M$ et al. Depressive and disruptive disorders and mental health service utilization in children and adolescents. J. Am. Acad. Child Adolesc. Psychiatry. 1999;38(9):1081-1090. doi: 10.1097/00004583-199909000-00010

20. Kataoka SH, Zhang L, Wells KB. Unmet need for mental health care among US children: Variation by ethnicity and insurance status. Am. J. Psychiatry. 2002; 159(9):1548-1555. doi: 10.1176/appi.ajp.159.9.1548

21. Bendit R, Gaiser W, Marbach JH. Youth and Housing in Germany and the European Union: Data and Trands on Housing: Biographical, Social and Political Aspect. Opladen: Springer Science \& Business Media; 2013. doi: 10.1007/978-3-663$11895-4$

22. Elliott DS, Huizinga D, Menard S. Multiple problem youth: Delinquency, substance use, and mental health problems. Springer Science \& Business Media; 2012

23. Lanes R. Diagnostic limitations of spontaneous growth hormone measurements in normally growing prepubertal children. Am. J. Dis. Child. 1989; 143(1 1):1284-1286

\section{Zheng W, McLerran DF, Rolland B, Zhang X,} Inove $M$, Matsuo $K$ et al. Association between body-mass index and risk of death in more than 1 million Asians. N. Engl. J. Med. 2011 ;364(8):719729. doi: 10.1056/NEJMoa1010679
25. Jabarouti $R$, Shariat $A$, Shariat A. Effect of Persian Classic Poetry on the Level of Stress Hormone in Retired Academicians. Poet. thrapy. 2014;27(1):1-9. doi: $10.1080 / 08893675.2014 .871809$

26. Shariat A, Malekpour M, Ghamarani, A. The Effect of Training Parents in Couples' Communication Model on Attention Deficit Hyperactivity Disorder Symptoms in 4-9 Year-Old Students in Isfahan. Int. J. Educ. Lit. Stud. 2013;1 (2):34-37. doi: 10.7575/aiac. ijels.v. 1 n.2p.34

27. Telles S. The Effect of Yoga on Mental Health of Children. Child Adolesc. Ment. Heal. New Dehli Sage Publ. 2012;219-227

28. Ross $A$, Thomas $S$. The health benefits of yoga and exercise: a review of comparison studies. J. Altern. Complement. Med. 2010;16(1)3-12. doi: $10.1089 / \mathrm{acm} .2009 .0044$

29. Archer RP, Buffington-Vollum JK, Stredny RV, Handel RW. A survey of psychological test use patterns among forensic psychologists. J. Pers. Assess. 2006;87(1):84-94

30. Lubin B, Larsen RM, Reed M, Matarazzo JD. Patterns of psychological test usage in the United States: 1935-1982. Am. Psychol. 1984;39(4):451 454

31. Baecke JA, Burema J, Frijters JE. A short questionnaire for the measurement of habitual physical activity in epidemiological studies. Am. J. Clin. Nutr. 1982;36(5):936-942

32. McHorney CA, Ware Jr, Raczek AE. The MOS 36-Item Short-Form Health Survey (SF-36): II. Psychometric and clinical tests of validity in measuring physical and mental health constructs. Med. Care. 1993;31(3):247-263

33. Shariat A, Tamrin SB, Arumugam $M$, Danaee $M$, Ramasamy R. Comparative reliability of different instruments used to measure the severity of musculoskeletal disorders in office workers. Work. 2016;54(3):753-8. doi: 10.3233/WOR-162313

34. Shariat A, Tamrin B, Arumugam M, Ramasamy 
R. The Bahasa Melayu Version of Cornell

Musculoskeletal Discomfort Questionnaire (CMDQ):

Reliability and Validity Study in Malaysia. Work A

J. Prev. Assesment Rehabil. 2016;54(1):171-178.

doi: 10.3233/WOR-162269

35. Sengupta P. Health impacts of yoga and pranayama: A state-of-the-art review. Int. J. Prev. Med. $2012 ; 3(7): 444-458$

36. Butterfield N. Yoga and mental health. Aust. Nurs. Midwifery J. 23(10):43

37. Kauts A, Sharma N. Effect of yoga on academic performance in relation to stress. Int. J. Yoga. 2009;2(1):39-43. doi: 10.4103/09736131.53860

38. Peck HL, Kehle TJ, Bray MA, Theodore LA. Yoga as an intervention for children with attention problems. School Psych. Rev. 2005;34(3):415-424.

39. Galantino ML, Galbavy R, Quinn L. Therapeutic effects of yoga for children: a systematic review of the literature. Pediatr. Phys. Ther. 2008;20(1):6680. doi: $10.1097 /$ PEP.0b013e31815f1 208

40. Elavsky S, McAuley E. Physical activity and mental health outcomes during menopause: a randomized controlled trial. Ann. Behav. Med. 2007;33(2):132-142. doi: $10.1080 / 08836610701307983$ 